\title{
Monumentos: são efeitos de que práticas?
}

\author{
Elizabeth Fontoura Dornelles ${ }^{1}$
}

\begin{abstract}
The text covers the impossible separation between scientific practice and ideology. Part of the first reflections of Michel Pêcheux - Thomas Herbert (1966 and 1967), where he explains, through historical materialism, how practical techniques mask the presence of ideology. Further supported by the ideas of Bauman (2000) and Escobar (1978), and having as an empirical object a product of the symbolic riograndense culture, shows how the masking of political practice occurs when the object is exposed to the work of interpretation.
\end{abstract}

Keywords: Scientific Practice; Practical Techniques; Ideology; Culture; Society; Politics.

Resumo: $\mathrm{O}$ texto trata da impossível separação entre prática científica e ideologia. Parte das primeiras reflexões de Michel Pêcheux - Thomas Herbert (1966 e 1967) onde ele explicita, via materialismo histórico, a forma como as práticas técnicas mascaram a presença da ideologia. Apoiado ainda nas ideias de Bauman (2000) e de Escobar (1978) e, tendo como objeto empírico um produto da cultura simbólica rio-grandense, mostra como ocorre o mascaramento da prática política quando o objeto é exposto ao trabalho da interpretação.

Palavras-chave: Prática Científica; Prática Técnica; Ideologia; Cultura; Sociedade. Política.

\section{Introdução}

A proposta de falarmos sobre práticas nasce da inquietação focada na reflexão que tenho feito dentro da pesquisa que vem sendo gestada e orienta o trabalho junto aos mestrandos do PPG em Práticas Socioculturais e Desenvolvimento Social. Quando ouço o sintagma práticas socioculturais várias perguntas surgem. A primeira: será que existe prática desconectada do social? Existindo, o que afinal é cultural e o que é social? Não havendo, onde é o ponto de encontro? Como se dá esse encontro?

Começaria a atender a provocação com a afirmação de Althusser (1978) "os homens concretos são sujeitos na história", feita no texto Sem sujeito nem fim. Na reflexão sobre práticas socioculturais, coloco o sujeito no seu lugar determinado pelo materialismo histórico. Nesse lugar teórico onde não se concebe o homem separado das práticas e nem as práticas isoladas umas das outras. O sujeito que transcende a sua individualidade, "sua interioridade psicológica", interage com o todo complexo da sociedade e sua experiência fica além de si, inscreve-se na história que o afeta e é afetada.

Para pensar essa não separação, é preciso fazer um avanço no pensamento marxista. Sair de Marx, passar pela releitura que lhe fez Althusser e chegar a Michel Pêcheux. Devemos ao marxismo, ou melhor, ao materialismo histórico, parte do alicerce teórico que constitui a disciplina de interpretação, Análise do Discurso - AD.

1 Docente da Universidade de Cruz Alta (UNICRUZ)-RS. 


\section{Práticas científicas e ideologias}

Nos textos iniciais de Michel Pêcheux, ainda como Thomas Herbert, cito dois: Reflexões sobre a situação teórica das ciências sociais e, especialmente, da psicologia social (1966) e Observações para uma teoria geral das Ideologias (1967) e ainda num dos seus últimos textos, Remontémonos de Spinoza a Foucault (1980), a ideologia e a contradição são objeto de reflexão profunda cujo argumento principal é a não separação entre a prática científica e a política.

Para fazer a crítica ao que considera a não cientificidade das ciências sociais, parte da demonstração do equívoco que o paradigma herdado do Iluminismo projeta sobre as ciências sociais ao impor-lhes uma separação entre a objetividade, demonstrável através dos procedimentos aplicáveis às ciências da natureza, e a subjetividade. $\mathrm{O}$ paradigma impunha e entendia a subjetividade como a negação do caráter científico o qual era efeito da filosofia idealista e da experimentação. A concepção de subjetividade estava pressuposta no sujeito cartesiano, portanto era individual, efeito de um eu onipotente. Ele aponta nesse texto para o que posteriormente tratará, mostrando que a subjetividade decorre da historicidade, função da história só possível no próprio movimento levado a efeito pelas práticas no interior da formação social.

Bauman (2000), ao tratar sobre as diferentes concepções ou funções que a ideologia tem recebido, reafirma a crítica de Herbert, ao mostrar que a ideologia surge para controlar a fidelidade da produção à lógica do pensamento. A função era a de ser guardiã da racionalidade pura. Já no Século XX, passa a ter um caráter anticientífico, pois deve dar espaço para o conhecimento fruto da experimentação, da manipulação empírica sobre o real, e não para as ideias abstratas. Diz o autor:

O termo "ideologia" passou assim do domínio do "conhecimento" para o terreno inferior das "crenças". Representava agora as crenças mais desarraigadas e ainda não superadas, falsas, equivocadas e perigosas, que arrogantemente resistiam ao teste do conhecimento; as crenças que a ciência jurara desmascarar, desautorizar e por fim eliminar da consciência humana na sua marcha para o inconteste domínio da razão. (p. 118)

A reflexão que nos apresenta Bauman aponta para a separação entre política, filosofia, ciência, e nessa conjuntura, a ideologia se transforma na nova tábua de salvação para a burguesia esclarecida que tem no combate à ideologia sua bandeira de luta, já que ela perturbava a validade científica. $\mathrm{O}$ que de modo alguma afasta a ciência da política. O que passamos a ver em Herbert parte desse estágio da noção de ideologia e o que esse texto de 1966 faz é colocar o ideológico no lugar que o Materialismo Histórico lhe constituiu.

Ao tratar sobre as práticas, Herbert (1966), toma como ponto de partida o modo como práticas técnica, ideológica e teórica se constituem na relação com a prática social. A prática técnica consiste num conjunto que compreende:

1 - A matéria prima sobre a qual ela se aplica;

2-Os instrumentos que ela utiliza, assim como a forma de trabalho humano que implicam; 3-O produto técnico obtido. (p. 28)

Na sequência ele descreve a forma como se dá a migração da prática social ou dos seus efeitos sobre a técnica. Diz:

Notamos imediatamente que a prática técnica se efetua tendo em vista o produto, ou dito de outra forma, que a técnica tem uma estrutura teleológica externa; ela vem preencher 
um desejo, uma falta, uma demanda que se define fora da própria técnica. O lugar onde se define a falta que indicará sua função em relação a esta técnica particular não é esta técnica, mas o todo organizado da própria prática social, quer dizer, em primeiro lugar, o modo de produção tal como o definimos. (grifo nosso) (idem, p.29)

A prática técnica produzirá uma simulação, como parte do mecanismo das ideologias tipo A, através do que reproduz o real. Como diz o autor (p. 31): "a técnica realiza o real sob uma forma manipulável". São procedimentos científicos, como a experimentação, a medição, a contagem, a criação de códigos, de descrições, ver o caso da Química e da Astronomia, que permitem manipular o real e produzir uma realidade que carregará os efeitos dessa ideologia técnica.

Isso tem o funcionamento de prover a prática da objetividade necessária, imposta pelo paradigma das ciências da natureza. Dessa forma, a temida subjetividade fica escamoteada, entretanto ela está sob a forma de ideologia do tipo B, presente nas práticas sociais que produziram a necessidade do produto, efeito da técnica. E que estará sempre presente nos usos que serão feitos do "invento", seja máquina ou técnica postos a serviço dos sujeitos na formação social. A própria ideologia opera fazendo o recalcamento de que o produto dessa técnica decorre de uma demanda vinda das práticas sociais e o seu produto voltará para elas.

A técnica que se demonstra adequada ao real passa a ser vista como dotada de cientificidade, validade para ser usada nas práticas sociais cujos resultados possam ser medidos, matematizáveis na lógica do $2+2=4$. Isso, entretanto, nas Ciências Sociais já se mostrou impraticável, conforme sabemos a partir do exemplo da Linguística que se funda como ciência sacrificando parte do seu objeto, a língua, quando retira dessa o aspecto individual, aquele que não se repete. Michel Pêcheux, ao longo da sua obra, busca trazer para a linguística o efeito das práticas sociais, exterioridade que havia sido desprezada pelo corte saussuriano. O que, em tentativas anteriores, como a sociolinguística, foi sem sucesso, pois não conseguiram ultrapassar a barreira das ideologias tipo B e continuaram na prática-técnica repetindo a divisão entre língua/exterioridade, ciência/ideologia.

A transmissão do produto dessa interpretação do real será administrada por ritos e sessões, sejam de ensinança ou de criação de códigos secretos. São práticas sociais como educação, caça às bruxas, intolerância às diferenças raciais ou de gênero que materializam a presença da ideologia no produto de práticas técnicas que devem guardar um caráter puramente científico sem a presença da "subjetividade".

Nos textos posteriores, Michel Pêcheux explicitará as relações entre ideologia, linguagem e práticas sociais, entretanto, como já se anunciou, não há práticas sociais sem a linguagem. Nessa reflexão de 1966, ele mostra que a transformação de uma prática técnica em prática política que será materializada nas práticas sociais se dá sob a forma de uma linguagem. Assim ele diz:

O instrumento de transformação da prática política é o discurso, como sistema articulado que remete a prática social complexa - seja ela sob a forma de mito ou sistema-compreende-se finalmente que a prática política tem por função transformar as relações sociais reformulando a demanda social (demanda é também comanda, no duplo sentido que entendemos daqui por diante), por meio de um discurso. (p. 35)

As práticas técnicas, efeito da demanda das práticas sociais, produzem objetos técnicos ou técnicas das quais apropriar-se-ão os sujeitos e as transformarão no interior da formação social numa comanda no sentido de que ali inscrever-se-ão, através de suas práticas políticas, consequentemente, discursivas. A transformação que deverá se operar será pela 
decorrência da explicitação da demanda vinda da prática social que foi incorporada e recalcada na/pela prática técnica.

Na primeira parte de Observações para uma teoria geral das ideologias, Herbert (1967) sustenta a impossibilidade de uma ciência ser considerada dicotomizando-se prática técnica e prática política.

Alerta para o fato de que prática técnica e prática política formam um elemento dentro da estrutura de uma prática. Remete então para a constituição dos objetos pelo duplo efeito do técnico e do político. Mostra que a prática social, na sua relação com a ciência, está na primeira fase da "transformação produtora" do objeto de uma ciência. O que fica encoberto pela a ideologia técnica, a do tipo A, que se encarrega de dissimular a presença da demanda vinda da prática social. É o momento do tipo teórico-conceptual. O segundo momento é quando se dá a "reprodução metódica" do seu objeto, pelo qual ela explora, do interior, o seu discurso para testar a coerência do objeto ou técnica.

Nas práticas sociais o efeito da prática teórico-conceptual será reproduzido como "realização do real". Um real que, como nos aponta Bauman (2000), para a ciência positivista é a autoridade suprema, inquestionável, que sustenta a cientificidade.

A experimentação, na prática social conceptual-experimental, feita no campo das relações dos sujeitos, faz circular as ideologias do tipo B, são elas que podem fazer revelar o momento primeiro que levou o cientista para o laboratório, a fase secreta, quando tudo deve parecer pura objetividade limpa de tudo aquilo que não for passível da demonstração técnica.

Pela possibilidade de resistência reveladora, o segundo momento constitui-se como condição indispensável da prática política, "ideologias tipo "B", “... estruturalmente ligada à sociedade como tal, onde desempenham o papel de cimento" (HERBERT, 1967, p. 65). Elas operam, como teorizou Althusser (1969/1996), através dos Aparelhos Ideológicos de Estado - AIEs e dos Aparelhos Repressivos de Estado - AREs.

Conforme Herbert (1966), os AIEs, esses que fazem a engrenagem da ideologia materializar-se e mover-se, como o educacional, o religioso, o jurídico, o cultural, são imprescindíveis na formação social. Fazem o trabalho com maestria e ao mesmo tempo dão conta de encobrir, deixar que as ideologias do tipo B continuem no seu papel de serem condições indispensáveis da prática política.

Conforme já tratei em Dorneles (2005), no texto de 1967, Thomas Herbert já mostra a sua preocupação em explicitar, a partir da dupla forma da ideologia (A e B), o modo como a prática vem impregnar a ciência de ideologia. Nessa busca, ele vai apontar para um novo paradigma para todas as ciências.

A não incorporação nas ciências sociais daquilo que lhes é mais próprio, impede que esses processos sejam transformados em objetos teóricos e apague-se a dicotomia entre ciência e ideologia. A consideração a esse amálgama entre ideologia, efeito das práticas sócio-históricas, e a ciência será a forma de conferir às ciências sociais a cientificidade que não poderá resultar da capacidade de fazer reprodução de um "real natural-sócio-histórico" atravessado por uma série de equívocos da ordem do ideológico. Nada escapa da ideologia, nem ciências sociais, nem ciências exatas.

É na historicidade que permeia, movimenta os processos sociais que se encadeiam constituindo as condições de produção de uma dada Formação Social, que está a sustentação científica para as ciências sociais ${ }^{2}$ poderem ver além da prática técnica e empírica.

2 Para fazer essa afirmação recorremos a Thomas Herbert, nome adotado por Michel Pêcheux, nos seus primeiros escritos. Ele nos mostra a presença da ideologia já no momento fundador de toda ciência. A ideologia, no modo como ele trata, nessa fase inicial, está diretamente tomada de Marx. A visão de Althusser, e dos AIEs, será convocada por Pêcheux mais tarde, quando trata do assujeitamento ideológico. 
Na figura que segue demonstro, a partir de dois eixos, o modo como operam a prática técnica, a fase de construção do objeto do conhecimento e produtora das ideologias tipo A, e a prática social, espaço da coleta da demanda, da concepção daquilo que será submetido ao paradigma das ciências, na perspectiva do Iluminismo, sempre tendo como modelo o das ciências da natureza. Espaço produtor das ideologias tipo B pelos "homens na história". Cabe esclarecer que uso "cientistas malucos" para ilustrar o isolamento do social, a assepsia absoluta, imposto pelo paradigma das ciências da natureza, em relação à subjetividade.

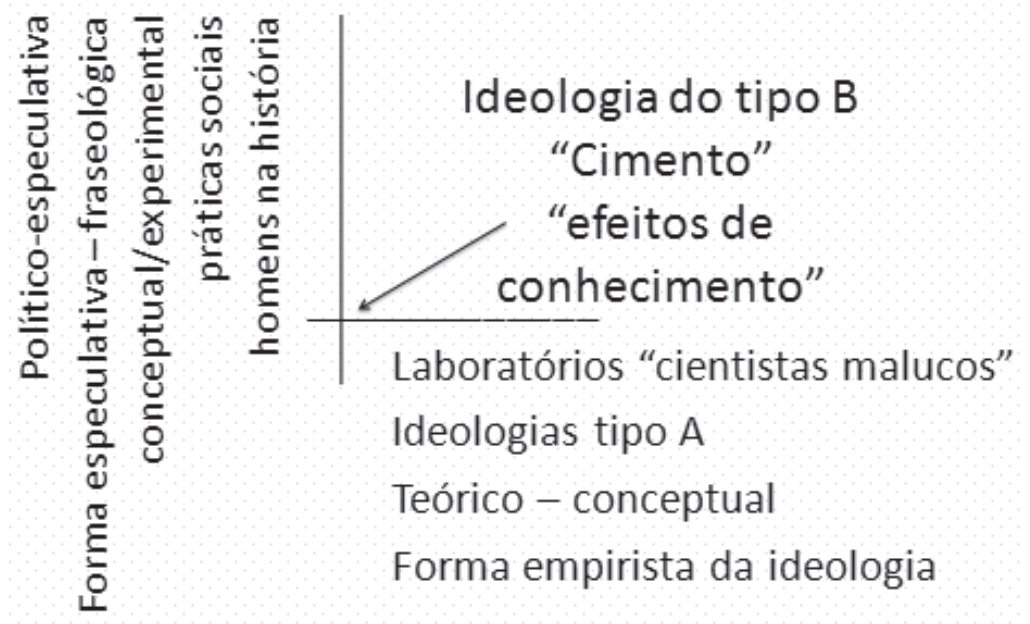

\section{Práticas culturais}

O real que é efeito das práticas técnicas e sociais apresenta-se como o todo estruturado sobre o qual novas práticas se instauram. Aquilo que se apresenta como o espaço dado é a formação social, delimitada pelo conjunto de práticas, normas, princípios, tradições que organizam determinado grupo. São elas que delimitam esse espaço, regulamentam as trocas sociais. É o real que rege o social e impõe-se ao sujeito que com ele relaciona-se.

A formação social, conforme já tratei em Dorneles (2005), é a realidade empírica que se apresenta como o já existente. Essa realidade resulta da historicidade que movimenta os processos sociais. A FS é regulada por códigos, por manuais de comportamento, por condutas tradicionais, por práticas sem que necessariamente tragam explicitadas as origens. São os espaços de visibilidade dos efeitos de processos desencadeados, organizados sob a forma de realidade que permite a ilusão de que isso é real. É nesse espaço que as práticas culturais se efetivam também numa perspectiva de processo submetido a uma série de equívocos decorrentes da prática social em que acontecem.

As práticas culturais tem uma ambiguidade advinda dos diferentes paradigmas adotados na definição de cultura. Uma primeira questão importante é a de que cultura pode ser dividida entre aquela que se confunde em alguns momentos com civilização e a cultura como arte, cultura simbólica.

É importante, entretanto, lembrarmos que ela é sempre uma linguagem ou um efeito de linguagem. Se pensada na perspectiva antropológica, veremos como nos aponta Bauman (2000), que a linguagem funda uma proibição, estabelece numa regra, como é o caso das 


\section{Conexão Letras}

relações incestuosas, a qual encaminha para determinadas práticas sociais. Na segunda perspectiva, a dimensão simbólica, a da representação, a cultura se funda pela anti-regra, já que foge do compromisso com a lógica, pode colocar o mundo de ponta cabeça.

As diferentes concepções e funções atribuídas à cultura estão atreladas aos momentos da história das ideias, da epistemologia que governa as ciências da natureza. Como já vimos em Herbert (1966,1967), as ciências sociais acompanharam as preocupações com a descrição, foco das ciências da natureza. A questão dos estudos culturais, embora o estágio técnico-especulativo possa mascarar a presença do social, mostram-se como espaço privilegiado para o agenciamento ideológico. A demanda satisfeita volta para que, a prática sociocultural faça a dissimulação da razão dos interesses de fora, por exemplo, pelo conhecimento da cultura do outro. Conhecê-la pode ser um caminho produtivo para dominar mercados, a economia, de um determinado país.

No caso dos estudos culturais eles devem não só interpretar aquilo que é a cultura do outro através de uma matriz que, no caso do Brasil, é a cultura europeia, mas reproduzi-la através de mecanismos implícitos nas práticas sociais.

A abordagem que estamos encaminhando no PPG em Práticas Socioculturais e Desenvolvimento Social considera que a amplitude de concepções de cultura não impõe exclusões para o analista dos processos culturais, entretanto há que se seguir uma coerência teórica. A concepção de cultura que mobilizamos é a de totalidade de uma dimensão do processo social. Para nós, então,

Cultura é a dimensão da sociedade que inclui todo conhecimento num sentido ampliado e todas as maneiras como esse conhecimento é expresso. É uma dimensão dinâmica, ela mesma em processo, uma dimensão fundamental das sociedades contemporâneas. (SANTOS, 2006, p. 50)

Essa dimensão se materializa nas práticas e, logo, é do campo das discursividades, tendo em vista que tais práticas trazem a presença do sujeito na história e nele se corporifica a linguagem e a ideologia. Nessa linha, tratarei da cultura na dimensão de AIE, como aparelho cultural que opera na forma de agenciadora das técnicas produtoras da simulação de um real assim "tão natural".

A reflexão de Escobar (1979), é ponto fundamental para encaminhar a compreensão dessa relação. Diz ele:

Se a noção de cultura é equívoca ela o é, precisamente, tanto por se constituir na noção-suporte de uma antropologia voltada a falsear a análise social pela realização "cultural" das relações humanas, quanto de incumbir-se, duplamente, tanto de isolar as práticas superestruturais de base, quanto na de se constituir na farsa de um discurso acima das contradições que sirvam de sustento ao aparelho cultural. (p. 184)

A introdução da noção de aparelho cultural estabelece a relação entre cultura e ideologia. Sabemos que a contradição é elemento fundamental nas relações sociais. A tentativa de, pela cultura, escamotear a contradição constitui-se numa estratégia para naturalizar sentidos, domesticá-los. A produção de um efeito de evidência coloca-se na contramão das práticas políticas democráticas.

Os objetos culturais estão submetidos aos múltiplos olhares e, o próprio conceito de cultura não pode ser simplificado, naturalizado, como livre da contradição produzida no 
espaço das práticas sociais. As práticas sociais, aquilo que ocorre na infraestrutura, na base dos processos levados a efeito pelo sujeito, da mesma forma que ocorre com a prática técnica, não poderá ser ignorado como efeito de prática social. Eles estão afetados pela superestrutura e a afetam, pois na prática sociocultural os objetos culturais se adensam e a reforçam. Um objeto cultural assume também a condição de produto de uma demanda. A cultura, enquanto AIE, apenas esforça-se para apresentar-se como não ideológica, ou como acima das classes.

Conforme Escobar (p. 187), a cultura atravessa todos os demais AIEs como aparelho transverso, onde as práticas culturais ajudam a sedimentar tanto as práticas realizadoras do efeito ideológico de sujeito quanto sustentam - em suas razões "civilizatórias" - os rituais de dominação que disciplinam por dentro os AIE.

Resgatando o que já vimos acerca das práticas técnicas e práticas políticas, efeito do social, cabe tratarmos da cultura na dimensão de prática que, impossível de ser de outra forma se não social, tem no sintagma práticas socioculturais a síntese de um processo. Começamos por ver que a cultura como dimensão do conhecimento opera na prática técnica através de certo escamoteamento da epistemologia da ciência no interior das teorias, como se elas fossem efeito de si mesmas.

Toda a ciência tem sua epistemologia e seu paradigma. A simplificação da ciência em teoria escamotea as bases filosóficas que a constituem, o que deixa fora do alcance da técnica o acesso a um conhecimento que permitiria chegar às práticas sociais, espaço onde a demanda se constituiu sob a presença das contradições. Momento como já vimos, da circulação das ideologias que funcionam através dos AIEs. A título de exemplo, cabe lembrar que um analista de discurso, filiado à $\mathrm{AD}$, não pode desconhecer a base epistemológica da Linguística, da Psicanálise, da História. Estamos num campo de outras disciplinas ou ciências, mas fazemos, sustentamos a diferença exatamente pela perspectiva epistemológica adotada na relação com essas disciplinas e ciências.

A técnica que é posta em circulação na formação social entra no circuito dos produtos a serem consumidos. Para Escobar, as concepções de cultura que a restringem ao campo, ao espaço da tão temível "subjetividade" são efeito da desconsideração ao paradigma que não admite a separação entre prática técnica e prática política. As questões do conhecimento, seus modos de produção e seus usos, estão ligados de modo indissociável às práticas socioculturais.

Escobar (1979), ao criticar um artigo de Ferreira Gullar, mostra que o equívoco que perpassa todo o artigo de Gullar é o fato de que esse "não admite a identificação da "cultura" com a ideologia, isto é, a cultura para ele se situa num terceiro lugar e é - o que agrava mais o equívoco de suas posições - confundida com as artes e as ciências." (p. 189)

A posição defendida naquele artigo está na contramão das práticas sociais concebidas como espaço onde se evidenciam todas as dimensões da existência humana, pois como diz Escobar (p. 189), "a sociedade é inseparável da dimensão ideológica e sabemos que a reprodução da sociedade como tal se faz pelas práticas, também ideológicas presentes e necessárias em todas as suas dimensões."

A cultura, nessa perspectiva, está submetida à contradição que atravessa a formação social e que se manifesta pelas lutas que, embora possam estar dissimuladas, são lutas de classe na perspectiva marxista. Desconhecer, por exemplo, que toda produção literária brasileira carrega efeitos da dominância da classe economicamente privilegiada torna-se possível na medida em que as próprias práticas socioculturais tem mecanismos para produzir tal efeito. Porém as práticas também atuam de modo a inverter posições dadas. Assim o destaque em que se colocam, diríamos, alguns produtos culturais, não significa 


\section{Conexão Letras}

sedimentação de posição. O objeto da prática técnica, isso que ganha um estatuto de real, não cessa de produzir novas realidades desde que é posto em circulação.

No âmbito da cultura simbólica podemos exemplificar com uma obra que surge a partir da demanda social da classe ruralista do Rio Grande do Sul que, através de gestões administrativas e técnicas, constitui o produto denominado Tradicionalismo, o qual produz uma cadeia de objetos, entre eles o monumento O Laçador.

Exposto o objeto ao trabalho da interpretação o mesmo vai se distanciando da demanda, efeito das ideologias tipo B, que estão na base da sua fase conceptual e passa a ser objeto de outras demandas, ainda que se estabeleça a contradição entre a que lhe deu origem e as demais.

Como podemos ver numa série usos do objeto simbólico feito pelas práticas socioculturais que reproduzem o produto cuja demanda da prática social que lhe motivou a existência está embutida no objeto e ficou silenciada pelas ideologias do tipo A. O aparelho cultural trabalha a ideologia não só pelo objeto que está exposto, mas pela reprodução que as práticas fazem do produto. $\mathrm{O}$ objeto vai ganhando ressignificações as quais podem inscrever outros efeitos de sentido para o Laçador. Na mesma proporção em que a cadeia de significantes se enriquece a cada novo uso que as práticas sociais fazem do Laçador, conforme podemos ver nas fotos um, dois e três, as práticas técnicas farão trabalhar as ideologias do tipo A, inscrevendo novos objetos nessa cadeia e criando novos elementos sustentadores da demanda que produziu o objeto.

Na figura abaixo, a partir dos dois eixos do paradigma da Linguística, faço uma ilustração de como a inscrição de novos objetos das práticas sociais no eixo da sintaxe e, na concepção da $\mathrm{AD}$, o do intradiscurso, reinscreve novos sentidos no eixo da semântica, o do interdiscurso para AD. Nesse movimento que envolve sujeito, linguagem, história e ideologia constitui-se a realidade cujo processo constitutivo só pode ser acessado pelas práticas científicas e políticas.

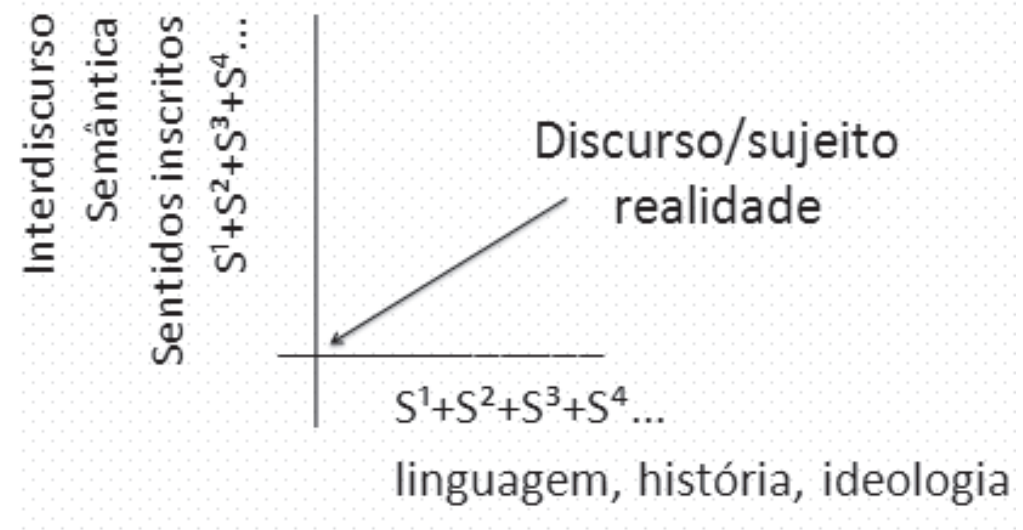

Sintaxe

Intradiscurso

Alguns dos diferentes significantes produzidos a partir da ressignificação do Laçador pelas práticas sociais estão configurados nas imagens abaixo, $\mathrm{Na}$ foto 1 , o monumento torna-se símbolo da campanha contra a AIDS ao receber o laço vermelho. 


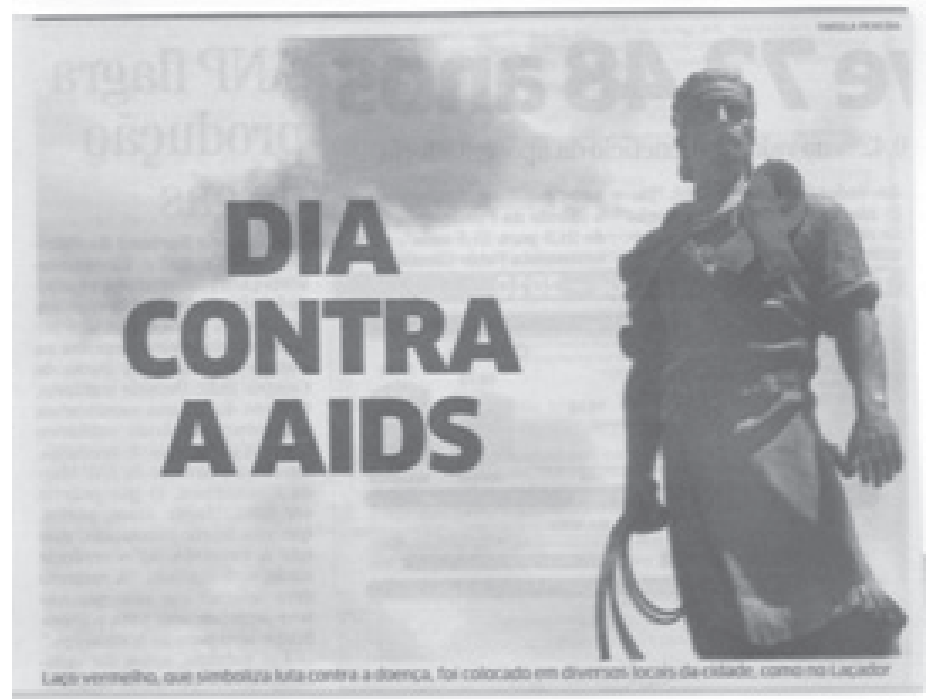

Jornal Correio do Povo (02/12/11)

A prática sociocultural expressa sob a forma de movimentos reivindicatórios por melhores salários e condições de trabalho se coloca aos pés do Laçador - foto 2 - com faixas e palavras que objetivam produzir a sensibilização social para a sua luta. A partir dessa composição de homens policiais vestidos de preto, faixas reivindicatórias e o símbolo do gauchismo podem produzir efeitos de sentido importantes para sua luta. Porém o que chama atenção é a contradição que a cena produz, apagada exatamente pelo efeito das práticas sociais. Não há mais resquício de luta de classes nesse gesto, todos são gaúchos lutando pela "Ordem e Progresso", luta onde os policiais tem significativa importância.

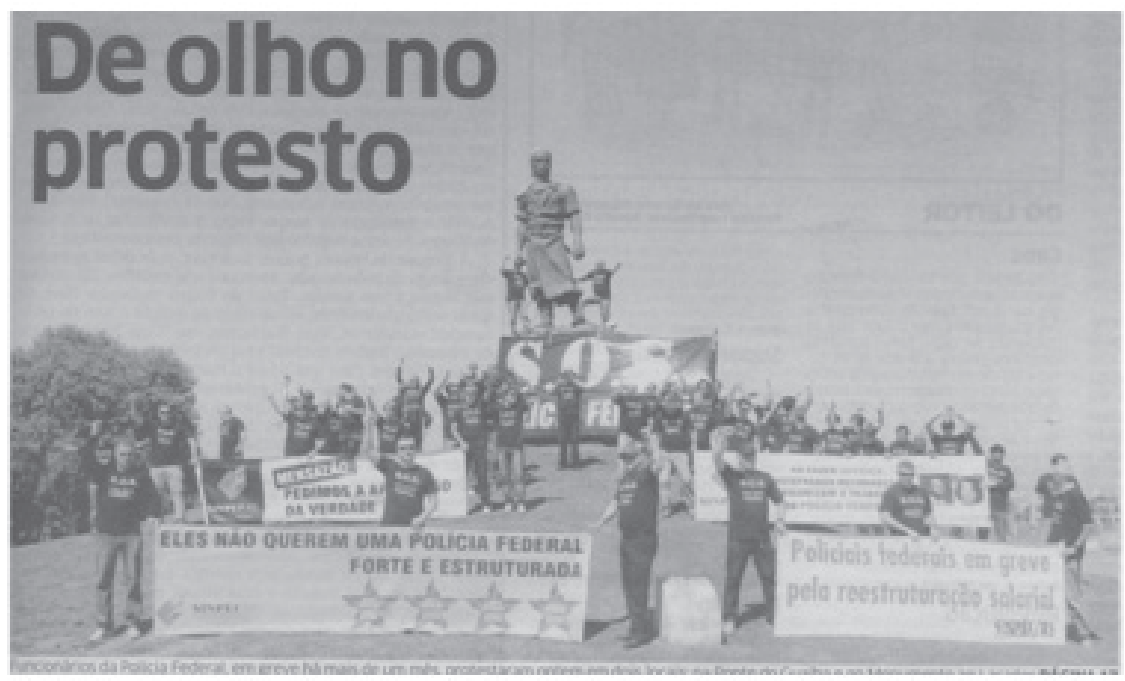




\section{Conexão Letras}

O mesmo objeto, em outras condições de produção, está sendo usado para evidenciar a luta entre ruralistas e trabalhadores rurais Sem Terra. Em 2004, no momento em que os Sem Terra deflagram o movimento Abril Vermelho, os ruralistas deflagram o Maio Verde. Assim desfraldam bandeiras verdes e vestem o Laçador de verde. E o monumento, objeto "cultural", "vestido" deixa transparecer a ideologia do tipo B, a demanda social que lhe deu origem.

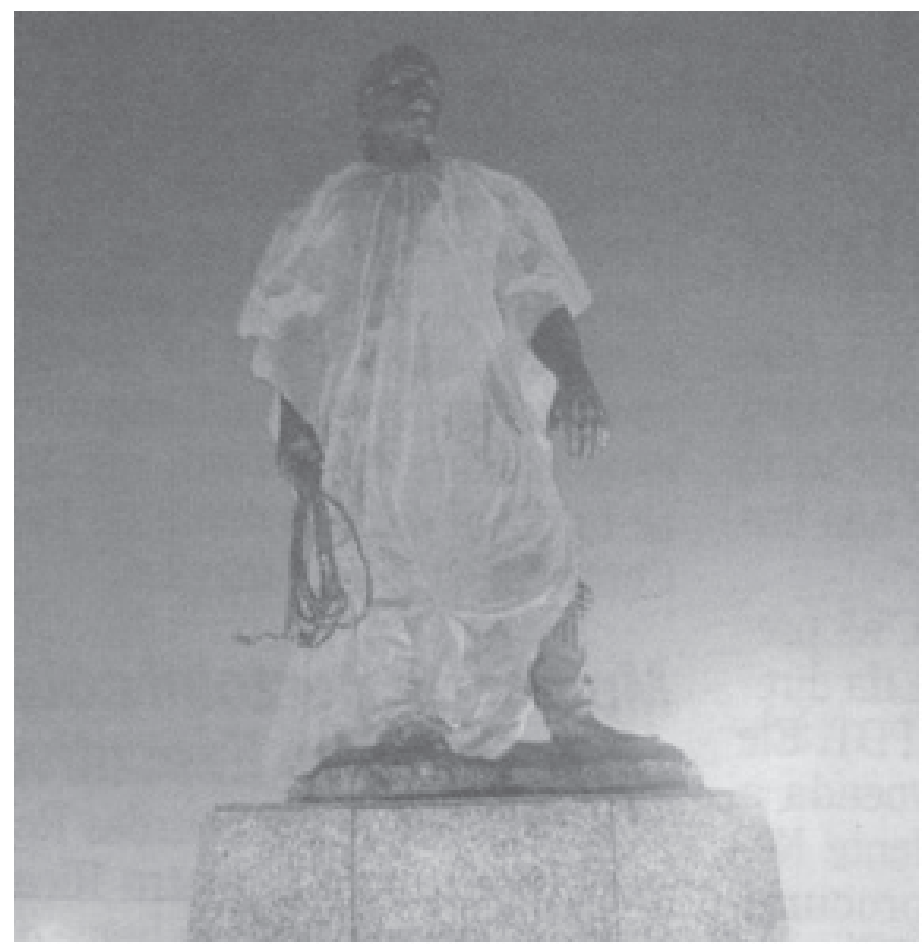

Jornal Correio do Povo (26/05/2004)

Importante lembrar que o poncho verde colocado sobre o monumento foi retirado por decisão judicial. Nesse episódio fica encoberto o fato de que foram os ruralistas que, há mais de cinquenta anos lançaram as bases do tradicionalismo do qual o monumento é produto. Nas práticas sociais o monumento tornou-se símbolo do Rio Grande do Sul e a prática técnica que o constitui encobriu a prática política que, nesses episódios de vestir o poncho e ter que retirá-lo, ressurge de modo contraditório.

\section{Conclusão}

A criação de condições para as práticas socioculturais moverem com o que parece estar sedimentado passa pelo desvelamento da prática política, daquela que no espaço das práticas sociais fez produzir uma demanda de modo velado. O produto das práticas técnicas, essas que fazem circular as ideologias do tipo A, carecem de análise na perspectiva política para podermos fazer aparecer a contradição que cria os produtos que, conforme tratamos, não são efeito puramente da fase teórico-técnica. 
A cultura está na história e reproduz/reforça pelas práticas a luta de classes no interior das mesmas e é exatamente por isso que trazemos para a reflexão acerca das práticas socioculturais a perspectiva do materialismo histórico. Ela não tem espaço como um "terceiro neutro", não ideológico. A reflexão de Michel Pêcheux, Thomas Herbert, tem enorme importância e atualidade para que possamos tratar as práticas socioculturais sem nos deixar atemorizar pelas perspectivas, às vezes catastróficas, que nos são apresentadas.

\section{Referências}

ALTHUSSER, Louis. (1969) Aparelhos Ideológicos de Estado. In: ZIZEK, Slavoj. Um mapa da ideologia. Rio de Janeiro: Contraponto, 1996.

Graal, 1978.

Observações sobre uma categoria: "Processo sem sujeito nem fim". In: Posições,

BAUMAN, Sigmund. Em busca da política. Rio de Janeiro: Zahar, 2000.

DORNELES, Elizabeth F. A dispersão do sujeito em lugares discursivos marcados.

Tese de Doutorado. Porto Alegre: UFRGS, 2005.

ESCOBAR, Carlos Henrique. Da categoria de cultura: do aparelho cultural de estado.

In: Encontros com a civilização brasileira. v. 16. Rio de Janeiro: Civilização Brasileira, 1979.

CORREIO DO POVO, edições de 26.5.04, 02.12.11 e 15.07.12.

HERBERT, Thomas (1966). Reflexões sobre a situação teórica das ciências sociais e, especialmente, da psicologia social. In: ORLANDI, Eni P. Análise de discurso: Michel

Pêcheux. Campinas: Pontes Editores, 2012.

. (1967) Observações para uma teoria geral das ideologias. In: Rua. Campinas, 1:63-89, 1995.

PÊCHEUX, Michel. Remontémonos de Spinoza a Foucault. In: El discurso politico.

México: Nueva Imagen, 1980.

SANTOS, José Luiz dos. O que é cultura. 16 ed. São Paulo: Brasiliense. 2006. 